\title{
GMR
}

\section{Mechanism of pingyangmycin-induced apoptosis of cultured human umbilical vein endothelial cells}

\author{
Y.D. Huang ${ }^{1 *}$, X. Tong ${ }^{2 *}$, Q. Chen ${ }^{1}$, S.W. Xia ${ }^{1}$, Y. Zhuo ${ }^{1}$, Z.H. Kang ${ }^{1}$ and \\ X.Y. Xue ${ }^{3}$ \\ ${ }^{1}$ Department of Otorhinolaryngology Head \& Neck Surgery of the First \\ Clinical College of Wenzhou Medical University, \\ The 118th Hospital of PLA, Wenzhou, Zhejiang, China \\ ${ }^{2}$ Department of Otorhinolaryngology Head and Neck Surgery, \\ Zhengzhou Central Hospital, Zhengzhou, China \\ ${ }^{3}$ Department of Microbiology and Immunology of Wenzhou Medical College, \\ Research Institute of Molecular Virology and Immunology, Wenzhou, \\ Zhejiang, China \\ *These authors contributed equally to this study. \\ Corresponding author: Y.D. Huang \\ E-mail: YidengHuangdoc@126.com \\ Genet. Mol. Res. 16 (2): gmr16029298 \\ Received September 16, 2016 \\ Accepted March 23, 2017 \\ Published May 10, 2017 \\ DOI http://dx.doi.org/10.4238/gmr16029298
}

Copyright (C) 2017 The Authors. This is an open-access article distributed under the terms of the Creative Commons Attribution ShareAlike (CC BY-SA) 4.0 License.

\begin{abstract}
In this study, we investigated the effects of pingyangmycin (PYM) on the growth inhibition and apoptosis of human umbilical vein endothelial cells (HUVEC). In this study, we aimed to explore the optimal concentration of PYM to induce the apoptosis of HUVEC and to determine its mechanism of action. After treatment of HUVEC with different concentrations of PYM for 24 $\mathrm{h}$, cell counting kit-8 (CCK-8) was used to detect growth inhibiting effects. Annexin V-FITC/propidium iodide stain was used to detect apoptosis, and western blot was used to detect the expression of glucose-related protein 78 (GPR78) and C/EBP homologous protein
\end{abstract}

Genetics and Molecular Research 16 (2): gmr16029298 
(CHOP) endoplasmic reticulum stress proteins. With increasing PYM concentration, the growth inhibition of HUVEC increased $(\mathrm{P}<0.05)$, the apoptotic numbers of HUVEC increased $(\mathrm{P}<0.05)$, with higher PYM concentrations inducing necrosis, and the protein expression of GRP78 and CHOP increased $(\mathrm{P}<0.05)$. PYM could obviously inhibit the proliferation and promote the apoptosis of HUVEC. Necrotic cells were more prevalent than apoptotic cells at high PYM concentrations. This study helped to determine the proper concentration of PYM to induce more apoptosis than necrosis, which is critical to minimize inflammation, enhance the healing of the skin, and maintain safety for the patient. PYM might induce HUVEC apoptosis through the endoplasmic reticulum stress pathway.

Key words: Angioma; C/Ebp-homologous protein; Pingyangmycin; Endoplasmic reticulum stress; Glucose-regulated protein 78

\section{INTRODUCTION}

Angiomas are one of the most common benign vascular lesions, with an incidence rate between 1:5000 and 1:10000 and 40\% of cases appearing in the head and neck (Zheng et al., 2013). Angiomas of the head and neck can severely affect the appearance of patients and can impede bodily function, emphasizing the importance of their timely treatment. Presently, major treatments include drug therapy, laser therapy, and surgical removal, either alone or as adjunct therapies (Keller and Patel, 2015). Laser and surgical treatments can fail to remove tumors completely, and they can affect the physical appearance of patients (Craig and Alster, 2013). Therefore, local injection of drugs is the preferred, initial method used to treat head and neck venous malformations (Zhang et al., 2016). Pingyangmycin (PYM, also called bleomycin A5), whose chemical name is N1-(3-((4-Aminobutyl)amino)propyl) bleomycinamide, is an antitumor glycopeptide antibiotic belonging to the bleomycin family, which is isolated from the soil in the Pingyang County of Zhejiang Province in China (Zhen and $\mathrm{Li}, 2009$ ). Studies have indicated that PYM is convenient to use, safe, and efficacious to treat angiomas of the head and neck (Xu et al., 2014; Xue et al., 2015). The effectiveness of treatment with PYM is determined by multiple factors. After injection, a large amount of PYM accumulates in the blood sinusoids to produce high local concentrations, which induces cell apoptosis (Huang et al., 2014; Huang et al., 2015; Peng et al., 2015) and causes oxidative damage (Segerman et al., 2013; Roy and Hecht, 2014). This inhibits the normal growth and metabolism of hemangioma endothelial cells (Yamamoto and Nishioka, 2005), injuring vascular endothelial cells and promoting remission of the angioma. Although the ability of PYM to induce apoptosis has been confirmed, its effective injectable dose and the mechanism of apoptosis induction require further study. There have been rare reports of the mechanisms of PYM-induced cell apoptosis, but they did not focus on angioma treatment. Angioma is caused by overproliferation of vascular endothelial cells. Human umbilical vein endothelial cells (HUVEC) also originated from a vascular endothelial cell population. In this article, HUVEC are used in vitro as a model to explore the effects and mechanisms of induction of apoptosis by PYM, with the aim to provide both a theoretical basis and new clues for the treatment of angiomas.

Genetics and Molecular Research 16 (2): gmr16029298 


\section{MATERIAL AND METHODS}

\section{Cell culture}

HUVEC were cultured in RPMI 1640 medium containing $10 \%$ fetal bovine serum (Gibco, NY, USA) and antibiotics (100 U/mL penicillin and $100 \mathrm{mg} / \mathrm{mL}$ streptomycin; Gibco, NY, USA) in a $5 \% \mathrm{CO}_{2}$ incubator (Thermo Fisher Scientific, USA) at $37^{\circ} \mathrm{C}$. When cells reached $70-80 \%$ confluency, they were passaged after digestion with $0.25 \%$ trypsin/EDTA (Gibco, USA).

\section{Preparation of PYM solution}

Sterilized PYM power (Taihe, Tianjin, China) was initially dissolved in PBS to produce a stock solution $\left(2 \times 10^{3} \mu \mathrm{g} / \mathrm{mL}\right)$ that was stored at $4^{\circ} \mathrm{C}$. Before an experiment, the stock solution was diluted to the required concentration with serum-free RPMI 1640.

\section{Inhibition of PYM on the proliferation of HUVEC by CCK-8 detection}

HUVECs were seeded into 96-well plates at $5 \times 10^{4}$ cells/well and cultured in a 5\% $\mathrm{CO}_{2}$ incubator (Thermo Fisher Scientific, USA) at $37^{\circ} \mathrm{C}$ until $60-70 \%$ confluent. The growth medium was replaced with $200 \mu \mathrm{L}$ serum-free medium, and PYM was added to a final concentration of $0,0.1,1,10,100$, or $1000 \mu \mathrm{g} / \mathrm{mL}$. There were five replicate wells for each PYM concentration. Plates were then cultured for 24,48 , or $72 \mathrm{~h}$. Ten microliters of CCK-8 (Tongren, Japan) were added into each well, followed by culturing for $3 \mathrm{~h}$. A dual wavelength spectrophotometer $(450 / 630 \mathrm{~nm})$ was used to measure the OD values. After $24 \mathrm{~h}$, the inhibition of HUVEC growth with different concentrations of PYM was calculated with the following formula: cell inhibition rate $(I R)=[1-(\mathrm{OD}$ value in treatment group - OD value in blank group) / (OD value in control group - OD value in blank group)] x 100\%. Each experiment was repeated three times to obtain a mean value.

\section{Detection of cell apoptosis rate by flow cytometry}

After treatment with PYM at $0.1,1,10$, and $100 \mu \mathrm{g} / \mathrm{mL}$ for $24 \mathrm{~h}$, which was stopped by FBS addition, cells in the treatment and control groups were collected, washed twice with PBS $(0.01 \mathrm{mM})$, and then transferred to Eppendorf tubes.

Annexin V-FITC $(200 \mu \mathrm{L})$ was added into each tube, and then $5 \mu \mathrm{L}$ Annexin V-FITC staining solution and $5 \mu \mathrm{L}$ of propidium iodide (PI) solution were added into the treatment and control groups (from BD Biosciences, San Diego, CA). After staining in the dark for 15 min and on ice for $10 \mathrm{~min}$, all tubes were analyzed by flow cytometry (BD Biosciences).

\section{Detection of GRP78 and CHOP by western blot assay}

After treatment with PYM at $0.1,1,10$, and $100 \mu \mathrm{g} / \mathrm{mL}$ for $24 \mathrm{~h}$, cells were centrifuged at $1000 \mathrm{rpm}$ for $5 \mathrm{~min}$, collected, washed with PBS, and then centrifuged to produce a cell pellet. To each tube, $150 \mu \mathrm{L}$ of RIPA lysis buffer (Bio-Rad, CA, USA) was added to each tube, mixed, kept on ice for $30 \mathrm{~min}$, and then centrifuged at $12000 \mathrm{rpm}$ for $10 \mathrm{~min}$. The

Genetics and Molecular Research 16 (2): gmr16029298 
supernatants were transferred into clean tubes and stored. The BCA method was used to detect total protein concentration. After SDS-PAGE, the proteins were transferred to PVDF membrane. Membranes were blocked with skim milk for $1.5 \mathrm{~h}$, and then incubated overnight at $4^{\circ} \mathrm{C}$ with anti- $\mathrm{C} / \mathrm{EBP}$ homologous protein (CHOP) antibody (dilution:1:1000, Abcam, MA, UK) or anti-glucose-regulated protein 78 (GRP78) antibody (dilution:1:1000, Cell Signaling Technologies, CA, USA). After washing the membranes, they were incubated at $37^{\circ} \mathrm{C}$ for $1.5 \mathrm{~h}$ with horseradish peroxidase-conjugated goat anti-mouse or goat anti-rabbit antibodies (dilution:1:5000). After washing the membranes again, an ECL kit (PerkinElmer, USA) was used to detect protein bands. Anti-glyceraldehyde 3-phosphate dehydrogenase (GAPDH, Xianzhi, Hangzhou, China) was used as the loading control.

\section{Statistical analysis}

All statistical analyses were done using the SPSS 20.0 software, and data are reported as means \pm standard deviation. One-way ANOVA and t-tests were used to analyze the differences between groups, and $\mathrm{P}<0.05$ denoted a significant statistical difference.

\section{RESULTS}

\section{Effect of PYM on the survival rate of HUVEC}

After treating with PYM for $24 \mathrm{~h}$, HUVEC numbers were clearly reduced. When the concentration of PYM ranged from 0.1 to $100 \mu \mathrm{g} / \mathrm{mL}$, the inhibitory effect on the HUVEC increased with increasing PYM concentration, and there was a significant difference among these groups $(\mathrm{P}<0.05)$. The inhibition of HUVEC was $91.24 \%$ at $100 \mu \mathrm{g} / \mathrm{mL}$ PYM and $92.39 \%$ at $1000 \mu \mathrm{g} / \mathrm{mL}$, but there was no statistically significant difference between these two groups $(\mathrm{P}>0.05$, Figure 1$)$.

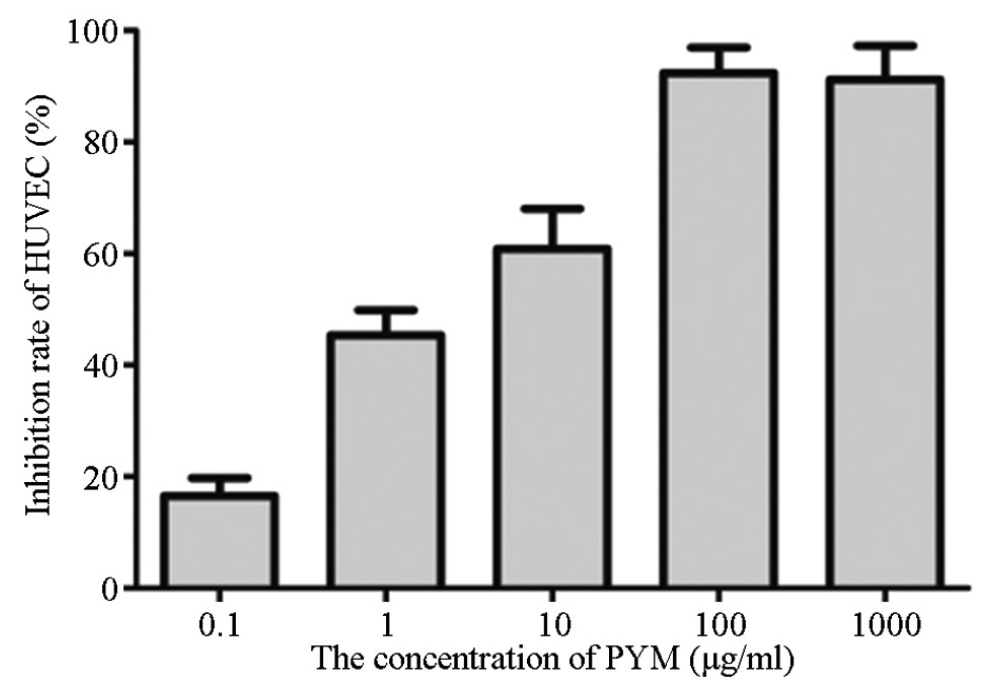

Figure 1. Inhibitory effect of PYM at different concentrations for $24 \mathrm{~h}$ on the growth inhibition of HUVEC. Abbreviations; HUVEC, human umbilical vein endothelial cells; PYM, pingyangmycin. 


\section{Induced apoptotic effect of PYM in the HUVEC}

Flow cytometry detected cell death by labeling with PI and Annexin V. After treating with PYM for $24 \mathrm{~h}$, cells in early apoptosis, and those in late apoptosis, and necrosis stained differently. Normal cells did not stain with Annexin V-FITC and PI (Q4 in Figure 2), earlystage apoptotic cells stained only with Annexin V-FITC (Q3 in Figure 2), and late-stage apoptotic and necrotic cells stained with both Annexin V-FITC and PI (Q2 in Figure 2). Cells from the Q1 were the detective error within the limits. The early apoptotic percentage of HUVEC was $1.59 \pm 0.56,12.7 \pm 1.57,24.7 \pm 6.99$, and $23.6 \pm 0.80 \%$ at $0,0.1,1$, and $10 \mu \mathrm{g} / \mathrm{mL}$ PYM, respectively. The late apoptotic and necrotic percentage of HUVEC was $4.87 \pm 2.09$, $7.32 \pm 3.88,39.1 \pm 6.18$, and $66.3 \pm 0.40 \%$ at $0,0.1,1$, and $10 \mu \mathrm{g} / \mathrm{mL}$ PYM, respectively. With an increase of PYM concentration, the apoptotic rate of HUVEC increased, and there were significant differences among treatment groups $(\mathrm{P}<0.05)$. When the concentration of PYM reached $100 \mu \mathrm{g} / \mathrm{mL}$, necrotic cells were prevalent (Figure 2).
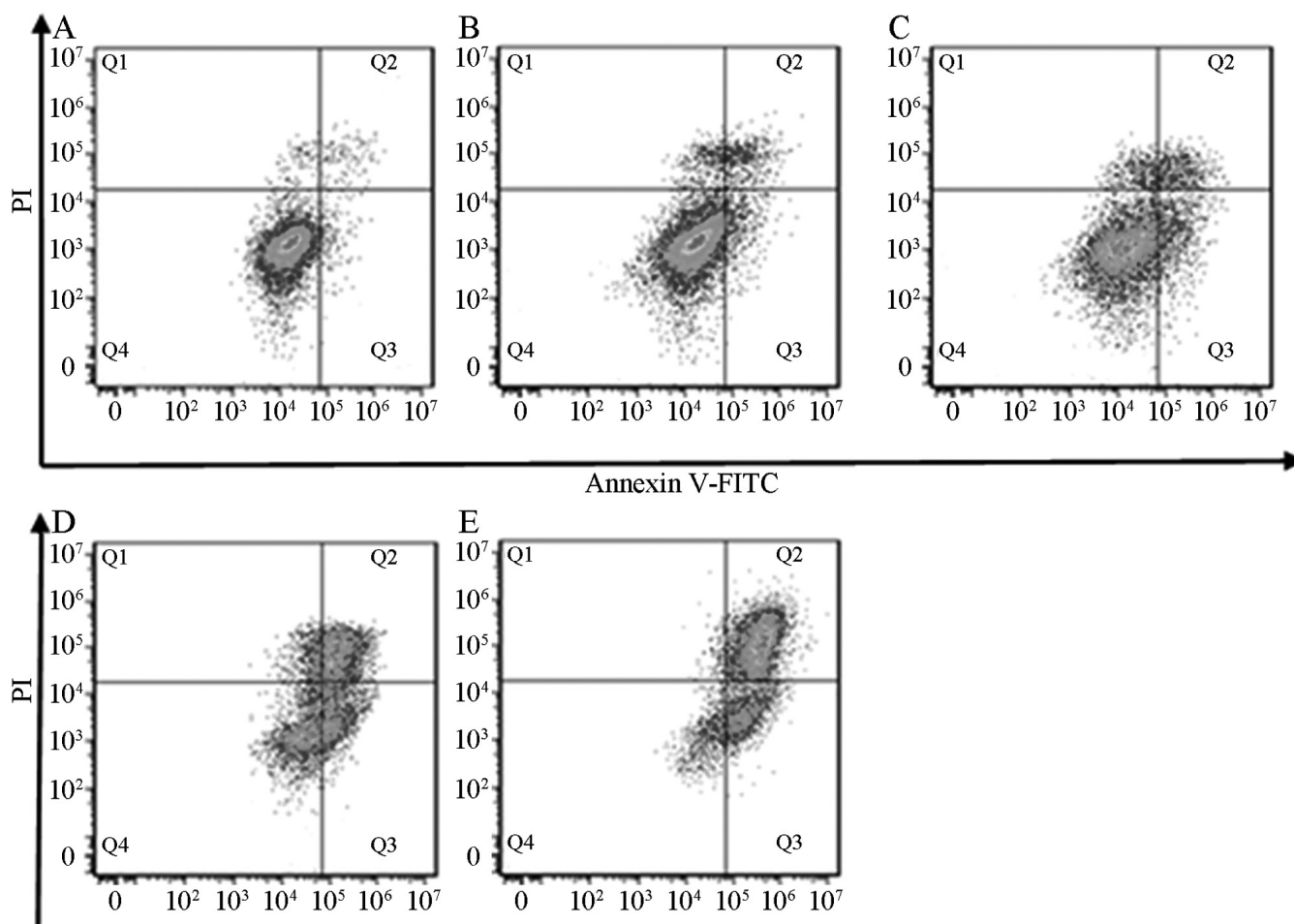

Annexin V-FITC

Figure 2. Effect of PYM at different concentrations for $24 \mathrm{~h}$ on the apoptosis of HUVEC. A. control group, B.-D. $0.1,1,10 \mu \mathrm{g} / \mathrm{mL}$ PYM groups, respectively. Compared with control group, with the increase of PYM concentration, the apoptotic percentage of HUVEC was increased $(\mathrm{P}<0.05)$; E. $100 \mu \mathrm{g} / \mathrm{mL}$ PYM group. Abbreviations: HUVEC, human umbilical vein endothelial cells; PI, propidium iodide; PYM, pingyangmycin.

Genetics and Molecular Research 16 (2): gmr16029298 


\section{Effect of PYM on the expression of GRP78 and CHOP proteins in the HUVEC}

After cells are damaged by hypoxia or drug toxicity, endoplasmic reticulum (ER) homeostasis is perturbed, causing the accumulation of unfolded or misfolded proteins in the ER. GRP78, as a sensor of ER stress, is a key factor to start the unfolded protein response (UPR) and regulate the ER steady state. Continuous or strong UPR induces regulators of cell apoptosis, such as CHOP, JNK, and caspases, to eliminate the impaired cell. After treatment with $0.1,1,10$, and $100 \mu \mathrm{g} / \mathrm{mL}$ PYM for $24 \mathrm{~h}$, protein expression of GRP78 and CHOP increased, and the difference between treatment and control groups was statistically significant $(\mathrm{P}<0.05)$. With an increase of PYM concentration, the protein expressions of GRP78 and CHOP also increased and reached a maximum at $10 \mu \mathrm{g} / \mathrm{mL}$ PYM, but were reduced at $100 \mu \mathrm{g} /$ $\mathrm{mL}$ PYM $(\mathrm{P}<0.05$, Figure 3).

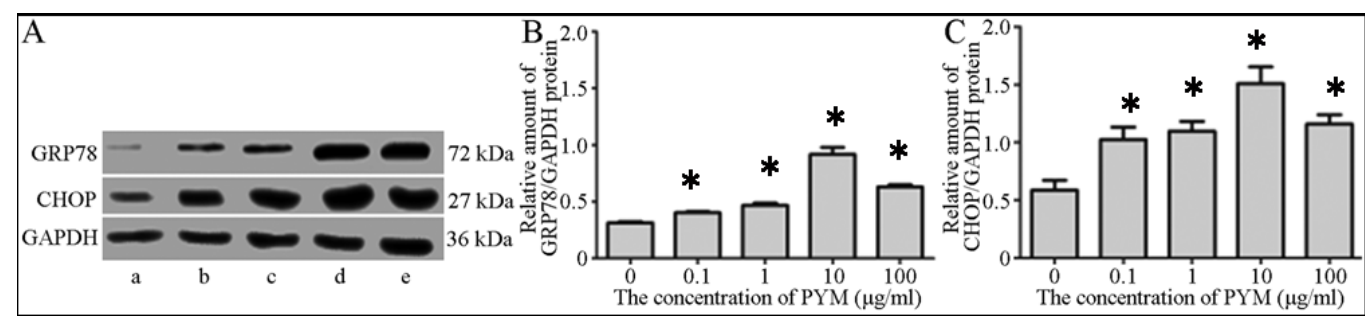

Figure 3. Protein expressions of GRP78 and CHOP were detected by western blot assay. Representative blots are shown in panel A, with quantification for GRP78 and CHOP shown in panels B and C, respectively. In panel A, lanes a-e represent groups treated with $0,0.1,1,10$, and $100 \mu \mathrm{g} / \mathrm{mL} \mathrm{PYM}$, respectively. ${ }^{*} \mathrm{P}<0.05$ compared to 0 $\mu \mathrm{g} / \mathrm{mL}$ PYM group. Abbreviations: PYM, pingyangmycin; GRP78, glucose-regulated protein 78; CHOP, C/EBP homologous protein.

\section{DISCUSSION}

Angiomas are common benign tumors in the head and neck, which severely affect patient appearance and function, and usually cause complications, such as pain, ulcers, bleeding, and invasion into nearby tissues (Buckmiller et al., 2010). These complications can seriously affect the ability to speak, breath, and swallow, and can even cause life-threatening massive hemorrhage or respiratory tract obstruction (Buckmiller et al., 2010). Many patients with angiomas are treated successfully with PYM. Our CCK-8 results confirmed that PYM inhibited the growth of HUVEC in a concentration-dependent manner. The inhibition reached $91.24 \%$ with $100 \mu \mathrm{g} / \mathrm{mL}$ PYM, which was not statistically different from that of the 1000 $\mu \mathrm{g} / \mathrm{mL}$ PYM group (P > 0.05, Figure 1). Thus, we used $0.1,1,10$, and $100 \mu \mathrm{g} / \mathrm{mL}$ PYM to perform the subsequent experiments. PI/Annexin V staining was used to detect cell apoptosis, and indicated that the rate of apoptosis increase was the largest when the concentration of PYM ranged from $0.1-10 \mu \mathrm{g} / \mathrm{mL}$. Once the concentration of PYM was over $100 \mu \mathrm{g} / \mathrm{mL}$, cell death occurred mostly from necrosis (Figure 2). Thus, according to the relationship between dose and effect of PYM, we can choose the proper concentration to exert pro-apoptotic effects, which is an important consideration to minimize inflammatory reactions, leading to improved patient safety and recovery after angioma treatment.

Genetics and Molecular Research 16 (2): gmr16029298 
Studies have indicated that PYM could treat angiomas by inducing vascular endothelial cell apoptosis (Zhao et al., 2004; Wang et al., 2010), but there has been no report of the signaling pathways involved in HUVEC apoptosis induced by PYM. This study has shown that PYM can induce HUVEC apoptosis and that the expression of GRP78 and CHOP proteins were much higher in the treatment group than in the control group, which suggests that PYM induced apoptosis of HUVEC through ER stress and the UPR pathway.

The UPR activates in the ER to protect the cell from damage and induce apoptosis if the damage is deemed too severe (Scull and Tabas, 2011). Under normal conditions, GRP78 is bound to PKR-like ER kinase (PERK), activating transcription factor 6 (ATF6), and inositol-requiring enzyme-1 (IRE1) in the ER, keeping them non-active. Under conditions of ER stress, unfolded protein accumulates in the ER, which makes GRP78 dislocate from the above three proteins to bind to unfolded proteins to help promote their correct folding. After dislocation, three pathways activate the UPR. 1) Activated PERK phosphorylates serine 51 of eIF $2 \alpha$ to promote expression of ATF4, which slows or stops the synthesis of protein (Kouroku et al., 2007). 2) Proteolytically activated ATF6 enters the nucleus as a homodimer or heterodimer combined with the Nuclear factor-Y to induce transcription of UPR-related genes (Kim et al., 2008). 3) Activated IRE-1 splices the XBP-1 mRNA that had been induced by ATF6. Spliced XBP-1 mRNA is translated to form active XBP1s, which increases the transcription of molecular chaperones that enhance the folding of ER proteins, and accelerate misfolded protein degradation (Wang et al., 2010). Increased GRP78 is widely considered an indicator of ER stress and UPR activation (Gonzalez-Gronow et al., 2009). Thus, the changes of GRP78 expression indirectly reflect the degree of ER stress. Western blot assays were used to detect GRP78 protein expression after treatment with PYM for $24 \mathrm{~h}$. We found that GRP78 expression was noticeably higher in the PYM group than in the control group $(\mathrm{P}<0.05)$, which indicated that PYM induced ER stress in the HUVEC. GRP78 expression declined when the concentration of PYM was $100 \mu \mathrm{g} / \mathrm{mL}$, which implied that the expression of GRP78 is limited and GRP78 has a limited capacity to respond to the ER stress state.

During severe or extended stress, apoptosis dominates. The three signaling pathways could initiate pathways mediated by ER stress to induce cell apoptosis to remove the injured cells. While they do not directly cause cell apoptosis, molecules, such as CHOP and JNK, activate downstream apoptotic signaling pathways (Szegezdi et al., 2006). CHOP is a specific transcriptional factor of ER stress (Oyadomari and Mori, 2004), belongs to the C/EBP family, and plays an important role in the cessation of cell growth and induction of cell death. Under non-stress conditions, CHOP has low expression, but its expression increases under conditions of ER stress. Overexpression of CHOP can promote cell apoptosis (McCullough et al., 2001). The Promoter region of the CHOP gene contains ATF4, ATF6, and XBP1s response elements, and it is an important molecule to promote cell apoptosis. The above UPR signaling pathways trigger the expression of CHOP, with the PERK- eIF2 $\alpha$-ATF4 pathway having the greatest impact in CHOP activation (Fels and Koumenis, 2006). Therefore, the activation of PERK signaling pathways initially has a protective effect by inhibiting protein synthesis and promoting cell survival. However, with prolonged ER stress, PERK promotes cell apoptosis by inducing CHOP expression. Our results showed that GRP78 and CHOP protein expressions were higher in the PYM treatment group than in the control group, which suggests that GRP78 expression increased, but $\mathrm{CHOP}$ expression also increased under the pathways activated by the ER stress. The expression of CHOP gradually increased when the concentration of PYM was $0.1,1$, and $10 \mu \mathrm{g} / \mathrm{mL}$, which indicated that the increased PYM concentration could increase

Genetics and Molecular Research 16 (2): gmr16029298 
the protein expression of CHOP in HUVEC to shift the cells toward apoptosis. Furthermore, the results of CHOP protein expression combined with the results of flow cytometry further indicated that PYM probably induced HUVEC apoptosis by activating the CHOP pathway. However, the expression of CHOP was lower in the $100 \mu \mathrm{g} / \mathrm{mL}$ PYM group than in the 10 $\mu \mathrm{g} / \mathrm{mL}$ PYM group. Possibly exceeding a certain PYM concentration increased necrotic cell death. Although the upstream regulatory mechanisms of CHOP are understood, there is no clear understanding about its downstream regulatory mechanisms. One current hypothesis is that the CHOP pathway downregulates Bcl-2 expression and increases reactive oxygen species (Tabas and Ron, 2011).

In summary, this study demonstrated that low concentrations of PYM increased the ER stress level in the HUVEC, and the pathway mediated by CHOP apoptosis might be one of the major mechanisms of the efficacy of PYM against angiomas. However, HUVEC were cultured in vitro in the present study. Additional experiments using animal models to determine whether there are any other signaling pathways remain a future direction. This article demonstrated the effect of PYM on the treatment of angiomas by inducing vascular endothelial cell apoptosis, and provided theoretical principles and new clues for the treatment of angiomas.

\section{Conflicts of interest}

All authors have no conflict of interest regarding this paper.

\section{REFERENCES}

Buckmiller LM, Richter GT and Suen JY (2010). Diagnosis and management of hemangiomas and vascular malformations of the head and neck. Oral Dis. 16: 405-418. http://dx.doi.org/10.1111/j.1601-0825.2010.01661.x

Craig LM and Alster TS (2013). Vascular skin lesions in children: a review of laser surgical and medical treatments. Dermatol. Surg. 39: 1137-1146. http://dx.doi.org/10.1111/dsu.12129

Fels DR and Koumenis C (2006). The PERK/eIF2 $\alpha /$ ATF4 module of the UPR in hypoxia resistance and tumor growth. Cancer Biol. Ther. 5: 723-728. http://dx.doi.org/10.4161/cbt.5.7.2967

Gonzalez-Gronow M, Selim MA, Papalas J and Pizzo SV (2009). GRP78: a multifunctional receptor on the cell surface. Antioxid. Redox Signal. 11: 2299-2306. http://dx.doi.org/10.1089/ars.2009.2568

Huang Y, Li P, Xia S, Zhuo Y, et al. (2014). Proapoptotic effect and the mechanism of action of pingyangmycin on cavernous hemangiomas. Exp. Ther. Med. 7: 473-477.

Huang YD, Li P, Tong X, He Y, et al. (2015). Effects of bleomycin A5 on caspase-3, P53, bcl-2 expression and telomerase activity in vascular endothelial cells. Indian J. Pharmacol. 47: 55-58. http://dx.doi.org/10.4103/0253-7613.150337

Keller RG and Patel KG (2015). Evidence-Based Medicine in the Treatment of Infantile Hemangiomas. Facial Plast. Surg. Clin. North Am. 23: 373-392. http://dx.doi.org/10.1016/j.fsc.2015.04.009

Kim I, Xu W and Reed JC (2008). Cell death and endoplasmic reticulum stress: disease relevance and therapeutic opportunities. Nat. Rev. Drug Discov. 7: 1013-1030. http://dx.doi.org/10.1038/nrd2755

Kouroku Y, Fujita E, Tanida I, Ueno T, et al. (2007). ER stress (PERK/eIF2alpha phosphorylation) mediates the polyglutamine-induced LC3 conversion, an essential step for autophagy formation. Cell Death Differ. 14: 230-239. http://dx.doi.org/10.1038/sj.cdd.4401984

McCullough KD, Martindale JL, Klotz LO, Aw TY, et al. (2001). Gadd153 sensitizes cells to endoplasmic reticulum stress by down-regulating Bcl2 and perturbing the cellular redox state. Mol. Cell. Biol. 21: 1249-1259. http://dx.doi. org/10.1128/MCB.21.4.1249-1259.2001

Oyadomari S and Mori M (2004). Roles of CHOP/GADD153 in endoplasmic reticulum stress. Cell Death Differ. 11: 381 389. http://dx.doi.org/10.1038/sj.cdd.4401373

PengLX,ZhaoP,ZhaoHS, PanE, etal.(2015). Phosphoinositide3-kinase/Aktpathway is involved in pingyangmycin-induced growth inhibition, apoptosis and reduction of invasive potential in EOMA mouse hemangioendothelioma cells. Mol. Med. Rep. 12: 8275-8281.

Genetics and Molecular Research 16 (2): gmr16029298 
Roy B and Hecht SM (2014). Hairpin DNA sequences bound strongly by bleomycin exhibit enhanced double-strand cleavage. J. Am. Chem. Soc. 136: 4382-4393. http://dx.doi.org/10.1021/ja500414a

Scull CM and Tabas I (2011). Mechanisms of ER stress-induced apoptosis in atherosclerosis. Arterioscler. Thromb. Vasc. Biol. 31: 2792-2797. http://dx.doi.org/10.1161/ATVBAHA.111.224881

Segerman ZJ, Roy B and Hecht SM (2013). Characterization of bleomycin-mediated cleavage of a hairpin DNA library. Biochemistry 52: 5315-5327. http://dx.doi.org/10.1021/bi400779r

Szegezdi E, Logue SE, Gorman AM and Samali A (2006). Mediators of endoplasmic reticulum stress-induced apoptosis. EMBO Rep. 7: 880-885. http://dx.doi.org/10.1038/sj.embor.7400779

Tabas I and Ron D (2011). Integrating the mechanisms of apoptosis induced by endoplasmic reticulum stress. Nat. Cell Biol. 13: 184-190. http://dx.doi.org/10.1038/ncb0311-184

Wang YA, Zheng JW, Zhu HG, Ye WM, et al. (2010). Sclerotherapy of voluminous venous malformation in head and neck with absolute ethanol under digital subtraction angiography guidance. Phlebology 25: 138-144. http://dx.doi. org/10.1258/phleb.2009.009019

Xu DP, Zhai QK, Cheng C, Gong H, et al. (2014). Appraisal of efficacy and safety of intralesional injection of high concentration of bleomycin A5 for treatment of huge macrocystic lymphatic malformations in cervical region. $J$. Craniofac. Surg. 25: 1707-1709. http://dx.doi.org/10.1097/SCS.0000000000000900

Xue L, Cao RY, Xu DP, Sun NN, et al. (2015). Percutaneous Treatment of Large Venous Malformations in the Oral and Maxillofacial Regions Using Electrochemical Therapy Combined With Pingyangmycin. J. Oral Maxillofac. Surg. 73: 1384-1391. http://dx.doi.org/10.1016/j.joms.2015.01.020

Yamamoto T and Nishioka K (2005). Cellular and molecular mechanisms of bleomycin-induced murine scleroderma: current update and future perspective. Exp. Dermatol. 14: 81-95. http://dx.doi.org/10.1111/j.0906-6705.2005.00280.x

Zhang L, Yuan WE and Zheng JW (2016). Pharmacological therapies for infantile hemangiomas: A clinical study in 853 consecutive patients using a standard treatment algorithm. Sci. Rep. 6: 21670. http://dx.doi.org/10.1038/srep21670

Zhao JH, Zhang WF and Zhao YF (2004). Sclerotherapy of oral and facial venous malformations with use of pingyangmycin and/or sodium morrhuate. Int. J. Oral Maxillofac. Surg. 33: 463-466. http://dx.doi.org/10.1016/j.ijom.2003.10.003

Zhen YS and Li DD (2009). Presently, major treatments include drugs therapy, laser therapy, and removal by operation or a combined therapy. Chin. J. Antibiot. 34: 577-580.

Zheng JW, Mai HM, Zhang L, Wang YA, et al. (2013). Guidelines for the treatment of head and neck venous malformations. Int. J. Clin. Exp. Med. 6: 377-389.

Genetics and Molecular Research 16 (2): gmr16029298 